This item was submitted to Loughborough's Research Repository by the author.

Items in Figshare are protected by copyright, with all rights reserved, unless otherwise indicated.

\title{
An intelligent information framework relating customer requirements and product characteristics
}

PLEASE CITE THE PUBLISHED VERSION

http://dx.doi.org/10.1016/S0166-3615(00)00074-9

PUBLISHER

(C) Elsevier

VERSION

AM (Accepted Manuscript)

LICENCE

CC BY-NC-ND 4.0

\section{REPOSITORY RECORD}

Harding, Jennifer A., K. Popplewell, Ying-Kit Fung, and Abdul R. Omar. 2019. "An Intelligent Information Framework Relating Customer Requirements and Product Characteristics". figshare.

https://hdl.handle.net/2134/9791. 
This item was submitted to Loughborough's Institutional Repository (https://dspace.lboro.ac.uk/) by the author and is made available under the following Creative Commons Licence conditions.

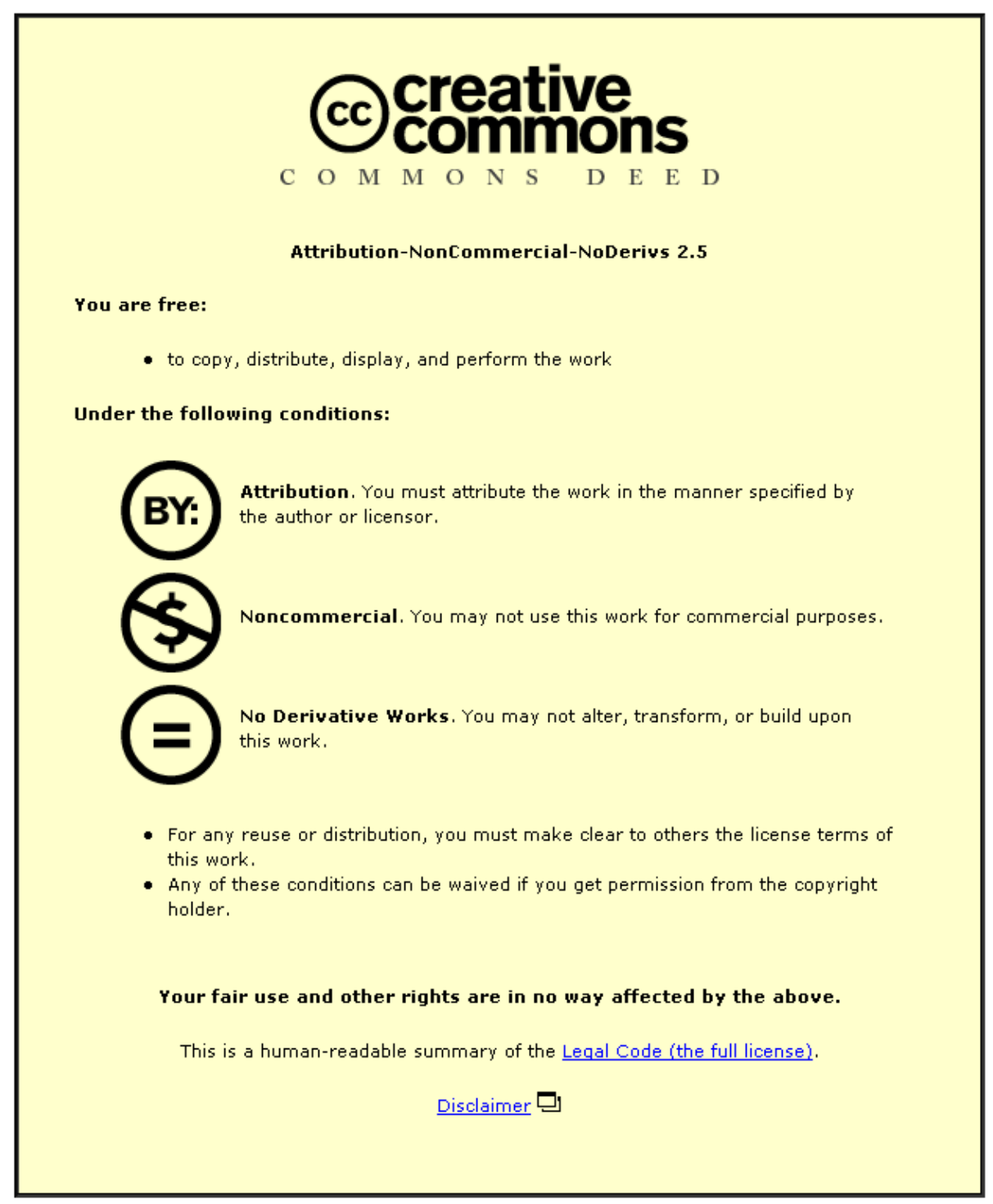

For the full text of this licence, please go to: http://creativecommons.org/licenses/by-nc-nd/2.5/ 


\section{An Intelligent Information Framework relating customer requirements and product characteristics}

By

\section{J A Harding*, K Popplewell*, R Y K Fung** and A R Omar***}

* Dept of Manufacturing Engineering, Loughborough University, Loughborough, Leicestershire. UK

** Dept of Manufacturing Engineering \& Engineering Management, City University of Hong Kong, 83 Tat Chee Avenue, Kowloon, Hong Kong, PR China.

*** Faculty of Mechanical Engineering, Mara Institute of Technology, 40450 Shah Alam,

Selangor Darul Ehsan, Malaysia. 


\begin{abstract}
Market driven strategies encourage enterprises to produce products that customers want to buy, and therefore can improve an enterprise's market position. Few organisations make effective use of market, competitor and customer information. Information modelling and intelligent support tools help define product specifications focused on fulfilling customer requirements and facilitating information sharing between members of extended design teams. Design effort can be targeted at particular product features, which yield maximum benefits for customer satisfaction. The Market Driven Design System provides comprehensive, intelligent support, meeting the challenges of effectively modelling, using and sharing valuable, yet imprecise, non-technical market information during product design.
\end{abstract}

\title{
Keywords: Quality Function Deployment (QFD) Information Modelling Information Sharing Concurrent Engineering Fuzzy Inference
}




\section{Introduction}

Manufacturing companies must meet the challenge of intense competition in many world markets. New product success or failure is strongly related to effective use of market information [1], and economy of scope, i.e. the ability to offer a wider range of customised services, is becoming increasingly important for gaining a competitive edge [2].

Gathering and sharing market information is important, but is only beneficial if the information is used effectively. This is not a straightforward task. Information must be shared across business and design functions and all parties need to develop a common understanding of the nature and importance of particular customer requirements. Interpretation of imprecise market information so that a multi-disciplinary design team can understand the customer's genuine requirements is very difficult and time consuming, and relies heavily on designer's intuition, since few, if any, effective software or other formal tools are available to help him.

The research reported here tackles several challenges posed during the process of translating imprecise, non-technical customer wishes into useful design specifications and market information, which can easily be shared between members of an extended design team. Depending on the nature of the product being designed, a design team will commonly include design engineers alongside specialists such as manufacturing engineers, electronics engineers, physicists, chemists, etc. The extended design team envisaged in this research includes, in addition, a wider range of experts, such as representatives from commercial areas, including sales and marketing, to provide earlier, more direct input of customer-

oriented issues. This paper provides a description of a software support system, which aids 
designers during the interpretation process, and converts inexact, natural language statements of customer needs into precise, quantified, product attributes. The system structures the market and design information within a database, so that it can easily be shared between design team members and it is available for future use as part of a full product model, which may be progressively populated throughout the design process. Additionally, the system can analyse the customer requirements, and product feature information, to prioritise aspects of the product where concentrated design effort should result in the greatest rewards in terms of customer satisfaction.

\section{Sharing Market Information}

Requirement information will be expressed in many different linguistic, inexact and probably qualitative ways. Successful enterprises require a thorough understanding of their customers, competitors and market related messages, so they can produce competitive products that satisfy customer requirements. Market orientation has been described as 'the organisationwide generation of market intelligence pertaining to current and future customer needs, dissemination of the intelligence across departments and organisation-wide responsiveness to $i t^{\prime}$ [3]. However, the fact that information about customer needs is collected, and that it is publicised to all members of a multi-functional design team, does not mean that producing a common response, i.e. a designed product which customers will want to buy, is an easy task. There are many challenges involved in getting people from different backgrounds, and disciplines to produce a common view of a product, as shown by research into computer systems to support concurrent engineering teams $[4,5]$. The task tackled here is particularly complicated since customer needs are often expressed in imprecise, non-technical terms. 
Products that the customer wants can only be delivered, in a systematic, rather than trial and error manner, if design engineers focus on market information throughout the design process. The research reported here aims to create an environment where this is possible. Figure 1 shows an extended design team sharing product information throughout the design process. In the early stages of the design process, each team member has their own view of the evolving product, based on their own area of expertise and contributions to the design. Also, designers commonly work with sketches, or models [6] rather than using computer based design tools, as these are useful tools to support creative ideas. But, it is very important for members of the design team to share information about the requirements and objectives of the design, right from the early conceptual stages, as they need to work towards sharing a common vision of the product, and its required functionality, performance, aesthetics, etc. as quickly as possible. Sharing computer-based design information can accelerate this process, particularly when design team members are based at different sites (which is increasingly common in global enterprises). By sharing the design information, through a product model, (which is a computer based representation of the product), a common view of the product will be produced.

Customer requirements, and the design specification, the implementation of which should satisfy the customer requirements, are important elements of the design information. In figure 1 , the design information is shown as cylinders, which represent databases.

\section{Take in Figure 1}

The rectangular blocks show software tools that team members may use to support their work, and the few shown here are merely representative of a whole range of possible support tools. The Market Driven Design System block has been highlighted, as this is the focus of 
the research reported here. The purpose of this system is to interpret raw, imprecise market information into clearly defined, genuine customer requirements, which can be populated into the product model. These customer requirements provide an accurate basis from which design engineers can produce a design specification. The specification defines characteristics, or features of the design. Inevitably, achieving some of these features will be more expensive or technically complex than others, and provision of some of the features will produce higher levels of customer satisfaction than others. It is therefore important to be able to prioritise design effort at different stages of the design process. The Market Driven Design System includes a mechanism for doing this. The functionality of the system falls into 3 areas, i.e., Clarification, Information Capture and Collection, and Evaluation (see figure 2).

\section{Take in Figure 2}

The Market Driven Design System provides Clarification for designers as follows. The inexact market information shown in figure 2 is commonly expressed in imprecise everyday language, and is normally expressed in descriptive, qualitative terms. Analysis and performance measurements are simplified if customer requirements are expressed in precise, quantitative terms wherever possible. Traditionally design engineers use their experience and intuition to translate imprecise customer requirements into a clearly defined design specification, but this is a less than ideal approach, as it leads to imperfect designs, which satisfy a design engineer's interpretation of customer requirements, rather than satisfying the genuine customer requirements. The Market Driven Design System uses an approach based on Fuzzy Logic to translate imprecise market information into clearly defined, quantitative terms. Initially the customer requirements are collected into groups of apparently similar 
needs; accurate groupings cannot be achieved until the meaning of imprecise customer requirement information has been clearly established. Product design characteristics (or features) which satisfy the customer requirements then need to be established, so that target values for these features can be identified. Traditionally, the task of setting the design targets relies primarily on the professional experience and intuition of designers and engineers. In contrast, this research interprets the customer requirements, through a series of techniques and methodologies, and thereby enables the design targets to be determined swiftly, quantitatively and consistently. The way in which this is tackled is described in detail in section 4, using hi-fi equipment as an example product.

The Market Driven Design System supports Information Capture and Collection by prompting users to indicate their requirements, likes and dislikes, for a given product, structuring the information for easy retrieval, and storing it within an object-oriented database system. Research has been carried out into ways of identifying customer needs and sorting them into a structured format $[7,8]$, this knowledge of customer requirements can then be incorporated into the product design information and translated into a design specification. Commonly, these approaches try to identify similarities between needs, so that the needs can be collected into groups, and/or split into different levels, a primary level for the most general needs and secondary and tertiary levels for more detailed description of the needs. Alternatively, needs may be grouped according to their impact, or importance, from the customer's perspective. Kano et al, [9] suggest that there are four groups of requirements, i.e. expected requirements, high-impact requirements, low-impact requirements and hidden requirements. The precise, prioritised customer requirements provide important information 
throughout the design process, and are therefore kept as part of the product model, so the information can be shared between design team members.

Once the customer requirements are determined, the product design can begin, and design characteristics (or features) which satisfy the customer requirements need to be established. A measure of how well individual characteristics satisfy particular requirements is also valuable, and should be stored as part of the product design information within the product model. Further essential specification information includes target values for the design characteristics, and these also need to be determined and added to the product model. The novel approach used in these evaluations is demonstrated, in section 4, using the hi-fi equipment example. Information relating to competitor products, and how well they satisfy (or fail to satisfy) customer requirements is also valuable. A detailed description of how all this market information may be structured within the product model database is given in section 5 .

The final area of functionality of the Market Driven Design System, is the support it provides to the design team for Evaluation of the design, in terms of how well the designed product provides customer satisfaction, and how the product could be improved to increase customer satisfaction. This is done by helping the design team to analyse and use the market information throughout the design process. The techniques adopted for presenting and analysing the quality of the product are based on Quality Function Deployment (QFD). This technique is described in section 3. Additionally, the Market Driven Design System provides support to focus valuable resources on aspects of the design where improvements will do 
most to raise customer satisfaction. Knowledge based algorithms are included to support the analysis and evaluation activities and this is described in section 6 .

\section{Quality Function Deployment}

The Market Driven Design System is designed to interact with design team members at various stages of the product life cycle, and present them with market information in a manner which clearly shows details of customer requirements, and how these are satisfied by characteristics of the product. It is also helpful if the team has knowledge of competitor products, and their strengths and weaknesses. QFD has been chosen as the medium for communication between the Market Driven Design System and human designers.

QFD is a well established, comprehensive quality system, which targets satisfaction of customer needs as a means of improving product quality $[10,11,12]$. The technique identifies customer needs and translates these into technical requirements. It has been widely adopted in various business sectors [13, 7], and when used enables problems and discrepancies in the product development and design process to be brought to the surface earlier [14]. Clausing [15] identified its great potential for use within concurrent engineering environments, since the technique enriches intercommunication between team members of different departments, identifies customers' needs and translates those needs into technical requirements. However, QFD is not always easy to implement, and companies have faced problems using QFD, particularly in large, complex systems [11]. Better use can be made of QFD through the use of intelligent software tools [16, 17], and the Market Driven Design System provides the required intelligent support. There are several different approaches to 
QFD, but the research reported here concentrates on the first phase of the Four Phase approach [18].

The first phase of the QFD methodology, production planning, provides the foundation for the remaining phases of QFD implementation. The customers' needs are listed, and then transformed into product features and functions, or design requirements. The tool associated with this first phase is called the House of Quality (HoQ) [10] or the quality table. The term HoQ is commonly used since the shape of the graphics resembles a shape of a house segmented into eight different compartments. This is depicted in figure 3, which shows marketing information required to populate the HoQ, and subsequently captured within a product model.

\section{Take in figure 3}

The Market Driven Design System guides the user to gather and generate the information content for the HoQ, and then, through the product model, links this to other aspects of product design information.

\section{Clarification of Customer Requirements for Product Specifications}

Section 1 of the HoQ, shown in figure 3, lists the customer needs. The challenge of translating, inexact, natural language statements of customer requirements into precise, accurate specifications with target values (section 8 of the HoQ), which satisfy genuine customer needs, is met by using an approach based on Fuzzy Set theory [19, 20]. The constructs of this fuzzy model for customer requirements interpretation are discussed below and are illustrated by using mid-range hi-fi equipment as an example product. Customer 
requirements can vary significantly in different customer categories, where categories may be based on different age groups or interest groups, etc. The customers considered in the hi-fi equipment example were aged between 20 and 30, as it is considered that this age group represents a large customer population for middle price range hi-fi equipment, and their requirements from the equipment are quite general and well understood within this customer population.

\subsection{The Fuzzy Spaces of Customer and Product Attributes}

An initial set of customer requirements was identified through interviews, and from magazines. These findings were categorised using an Affinity Diagram, [21] and a series of customer surveys were then conducted to gather detailed information on the set of customer requirements (see Table 1), to enable the entries for section 1 of the HOQ to be identified. So, for example, under a category Good Sound Quality and Features, several entries were identified, including, (1) Strong Bass, (2) Reality, low loss and noise, (3) Natural Sounds, (4) Output Power, etc. An Analytic Hierarchy Process (AHP) [22, 23] was then carried out, to identify the relative weights of importance of the identified customer requirements. AHP has been successfully applied to help set priorities in a wide variety of problem areas, including marketing strategies [24, 25] and total quality management [26].

An initial set of product characteristics (design features) for section 3 of the HoQ was identified through reviewing best-selling trade magazines, and from discussions with designers from hi-fi manufacturing companies. The characteristics were considered at two levels, the first including the main units, for example, CD player, amplifier, bass loud speaker, tuner, and cassette deck. The second level detailed components within these units, 
so, for example, components within the bass loud speaker unit included the number of drive units in the speaker, diameter of unit, size of speaker box, location of drive units within speaker box, box material, sensitivity, bass roll off and output power. The relationship and correlation matrices were completed with support from the designers and engineers. The relative weights of importance of individual characteristics were determined using an AHP exercise with support from the designers and engineers. The design target for each product characteristic are critical factors to the ultimate success of the design, as they provide the specification which determines how well the identified customer requirements are satisfied by the product. Traditionally, the target values are set by design engineers, based on their knowledge and experience of the product type. In this research, an approximate reasoning approach, using fuzzy inference has been adopted to derive these design target values.

The approximate reasoning approach uses knowledge from a fuzzy rule base which contains heuristics and design knowledge about the relationships between customer requirements and product characteristics. Hence, the customer requirements which have been identified for section 1 of the HoQ and the product characteristics which have been identified for section 3 of the HoQ, need to be considered in terms of fuzzy vectors and sets.

The set of model variables representing the customer requirements (attributes) for a given product can be denoted by an $N$-dimensional fuzzy vector $X$, such that

$$
X=\left(X_{1}, X_{2}, \ldots, X_{N}\right) \quad \text { in the fuzzy space of } V
$$

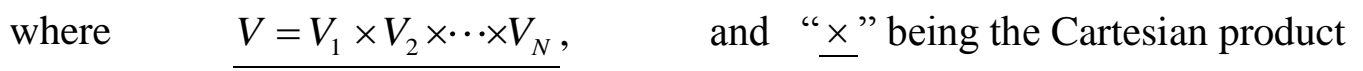


i.e. the $i^{\text {th }}$ input model variable (customer attribute) $X_{i}$ of a given product, for instance, the "Output Power" of the Hi-Fi system, can be defined in the crisp set $V_{i}(i=1,2, \ldots, N)$ which represents the corresponding universe of discourse, say from $100 \mathrm{~dB}$ to $115 \mathrm{~dB}$. For example, Output Power might be represented by 6 evenly spaced, discrete domain points, $(100,103,106,109,112,115)$.

Similarly, the set of model variables representing the product / engineering characteristics can be denoted by an $M$-dimensional fuzzy vector $Y$, such that

\begin{tabular}{|c|c|c|}
\hline & $Y=\left(Y_{1}, Y_{2}, \ldots, Y_{M}\right)$ & in the fuzzy space of $P$, \\
\hline where & $P=P_{1} \times P_{2} \times \cdots \times P_{M}$ & and " $x$ " being the Cartesian product \\
\hline
\end{tabular}

i.e. the $i^{\text {th }}$ output model variable (product attributes) $Y_{i}$, for instance the Diameter of the Bass Unit of a bass loud speaker unit can be defined in the crisp set $\underline{P_{i}}(i=1,2, \ldots, M)$ which covers the corresponding universe of discourse, say from $100 \mathrm{~mm}$ to $300 \mathrm{~mm}$. For example, the Diameter of the Bass Unit might be represented by 6 evenly spaced, discrete domain points, $(100,140,180,220,260,300)$.

\subsection{The Fuzzy Inference Process}

\section{Take in Figure 4}

The fuzzy inference process covers the activities of fuzzification, rule evaluation, aggregation and defuzzification as illustrated in Figure 4, and this results in crisp target values for the product characteristics. The following example explains how this is achieved. 
When a set of customer requirements have been identified for a product, the attributes are first fuzzified according to the term sets (sets of linguistic variables) of the relevant model variables and modified by the fuzzy set hedges as appropriate in order to fully elaborate on the customer attributes. This is demonstrated below.

A general linguistic variable (fuzzy set) $x_{i}$ for customer attribute $X_{i}$ defined on the universe of discourse $V_{i}$ in the space of $V$ can be denoted by a membership function, $A_{i}$, such that

$$
A_{i}=\left(\mu_{i 1}, \mu_{i 2}, \cdots, \mu_{i n_{i}}\right)(i=1,2, \ldots, N)
$$

where $\mu_{i l}\left(l=1,2, \ldots, n_{i}\right)$ is a real number from the interval $[0,1]$ representing the grade of certainty for the fuzzy set $x_{i}$ against the domain point $v_{i l}$ in $V_{i}$.

So, for example, the customer requirement, output power was defined above as having a value between $100 \mathrm{db}$ and $115 \mathrm{db}$, represented by the discrete domain points, (100, 103, 106, $109,112,115)$. In the course of fuzzification, 3 fuzzy sets for low output power, medium output power and high output power could then be defined, and these would show the grades of certainty for each of the 6 domain points. For example,

$\begin{array}{llll}\text { Fuzzy set [1] } & \text { Low } & {[1.00,0.75,0.50,0.25,0.00,0.00]} \\ \text { Fuzzy set [2] } & \text { Medium } & {[0.32,0.65,1.00,0.75,0.50,0.20]} \\ \text { Fuzzy set [3] } & \text { High } & {[0.00,0.06,0.20,0.40,0.60,1.00]}\end{array}$

This process is applied to all the customer requirements. 
Similarly, for the corresponding product characteristics $Y_{j}$, there exists a linguistic variable $y_{j l}$ defined over a specific domain in the universe of discourse of $Y_{i}$ in the output space of $P$. The membership function of $y_{j l}\left(l=1,2, \ldots, m_{j}\right)(j=1,2, \ldots, M)$ can be expressed as:

$$
\underline{B_{j l}=\left(\eta_{j 1}, \eta_{j 2}, \cdots, \eta_{j m_{j}}\right)}
$$

So, for example, the product characteristic, diameter of bass unit was defined above as having a value between $100 \mathrm{~mm}$ to $300 \mathrm{~mm}$, represented by the discrete domain points, (100, $140,180,220,260,300)$. In the course of fuzzification, 4 fuzzy sets for small diameter, medium diameter, large diameter and very large diameter could then be defined, and these would show the grades of certainty for each of the 6 domain points. For example,

$\begin{array}{lll}\text { Fuzzy set [1] } & \text { Small } & {[0.44,1.00,0.50,0.25,0.00,0.00]} \\ \text { Fuzzy set [2] } & \text { Medium } & {[0.00,0.75,1.00,0.30,0.15,0.00]} \\ \text { Fuzzy set [3] } & \text { Large } & {[0.00,0.30,0.78,1.00,0.80,0.45]} \\ \text { Fuzzy set [4] } & \text { Very Large } & {[0.00,0.15,0.60,0.83,1.00,1.00]}\end{array}$

This process is applied to all the product characteristics.

A general fuzzy rule, $R_{i}$ relating a number of customer attributes $X_{i}$ with linguistic variables $x_{i}(i=1,2, \ldots, N)$ to product attributes $Y_{j}$ with linguistic variable $y_{j l}$ can be expressed as:

$$
\begin{gathered}
R_{i} \text { : If } X_{1} \text { is } x_{1} \text {, and } X_{2} \text { is } x_{2} \text {, and..., } X_{N} \text { is } x_{N} \text {, } \\
\text { then } Y_{j} \text { is } y_{j l}(j=1,2, \ldots, M) \text { and }\left(l=1,2, \ldots, m_{j}\right)
\end{gathered}
$$

and, the confidence of the designers / engineers on this rule can be denoted by a Certainty Factor, $r_{i}$. Using this fact, a fuzzy rule base was developed, to capture the design knowledge 
and experience, defining the relationships between customer requirements and product characteristics. Hence, the rule base consisted of rules structured like the following:

If $\quad$ Bass is strong

Output Power is high and

Reality is high

Then

Diameter of Bass Unit is very large.

A Condition Matrix $C_{i}$ for the above rule $R_{i}$ can be produced by combining the appropriate fuzzy sets for the 3 product requirements listed in the 'If' statement. This condition matrix can also be transformed into a Conditions Vector, $\bar{C}_{i}$ and when this is combined with the appropriate fuzzy set for the product characteristic $Y_{j}$ given in the 'then' part of the rule, a Rule Matrix $Q$, is produced. If there are several rules relating to a particular product characteristic in the fuzzy rule-base, these matrices can be combined into a Consolidated Rule Matrix. The matrices produced in this way are large, and it is not considered appropriate to include them here. Full details of their construction are provided in [27].

\subsection{Applying the Fuzzy Customer Requirement Inference System}

Once the knowledge base for a product has been established, the system is ready to process specific customer requirements. To start with, the specific requirements are represented by the relevant model variables $X_{i}$ with the suitable fuzzy sets $x_{i}$ in the space $V_{i}$ with membership function vectors $A_{i}^{\prime}$. The membership function vectors $A_{i}^{\prime}=\left(\mu_{i 1}^{\prime}, \mu_{i 2}^{\prime}\right.$, $\left.\mu^{\prime}{ }_{i 3,}, \ldots \ldots, \mu_{i n}^{\prime}\right)$, where $\mu_{i l}^{\prime}$ is a number from the real interval $[0,1](i=1,2,3, \ldots, N),(l=$ 
$1,2,3, \ldots, n)$, representing the grade of certainty at the point $v_{i l}$ in $V_{i}$. This is the same approach to fuzzification that was shown in section 4.2 , but this time it is carried out on specific requirements. So, using the hi-fi example to demonstrate this process, the results of our customer surveys may have identified the following specific requirements in the category of Good Sound Quality and Features,

- Bass should be "fairly strong"

- Output Power should be "extremely high" and

- Reality should be "above average acceptable"

New fuzzy sets may need to be created from the existing ones, for example here we have a requirement for "extremely high" output power, whereas our original 'nearest' fuzzy set was for 'high' output power.

The software then evaluates the fuzzy rule-base against the input customer requirements, and draws some sub-conclusions. Sub-conclusions drawn from rule evaluation are then aggregated into one or more complete conclusions in the relevant output fuzzy regions. As a result, an output membership vector, $B_{j}{ }_{j}$ is obtained by evaluating the fuzzy rule-base between customer requirements and product attributes. The grade of certainty at each domain point $p_{j l}$ will be a real number from the interval $[0,1]$. The approach used is based on Max-Min Compositional Operation [28], and full details are given in [27].

The design targets for each product characteristic can be established by defuzzifying the output membership vector $B_{j}^{\prime}$., i.e. by combining the resulting grades of certainty with the original discrete domain points representing the particular product characteristic. The centroid method for defuzzification was used in this research on a detailed version of the hi-fi 
example, and a minimum diameter of 224.3 was predicted for the bass loudspeaker unit. The use of fuzzy inference on the attribute knowledge base to determine the target value for design features is a novel concept.

\section{Capture and Collection of Market Information within a Product Model}

A major strength of the Market Driven Design System is that the market information and its relationships to the product design, is captured throughout the product life cycle, and the resulting information can be freely shared between design team members. This has been achieved as the analysed market information has been modelled as part of a product model. Use of product models is increasingly common in both industry and research [29, 30]. A product model is a representation of a product in a computer, and can contain all the information relating to the product from concept through to disposal, including specification information [31]. In this research, the product model is enhanced by the addition of market information and specification detail in the form of the design targets identified using fuzzy inference.

\section{Take in figure 5}

The information has been modelled by examining the main elements of a product, its HoQ, and by defining the key elements as objects. The information content, or state of the objects, their behaviour and inter actions, have been determined by considering the relationships between information within the HoQ and its relationship to other product design information, which is commonly captured within product models. A class structure has been designed, based on this study, using object oriented methods [32]. The product model structure used in

this research is shown using the Unified Modeling Language (UML), in figure 5. Links 
between the QFD relevant information and the remainder of the product information, through the class Product, are now described in detail.

The first segment of the HoQ in figure 3 represents the Voice of the Customer, or the Customer Needs. There are two types of customer needs that should be stored in the product model, the original customer statements of needs (Customer_Requirements), and the product attributes that are displayed through the QFD interface. Each Customer_Requirement object can be linked to one or more Need object, which holds information for section 1 of the HoQ. The hierarchical method described by Ulrich and Eppinger [8] organises needs into different levels, a primary level for the most general needs and secondary and tertiary levels for more detailed description of the needs. The method then establishes a relative importance for each of the needs. A similar hierarchical structure has been adopted in the current research. Two classes Primary_Need and Need have been designed and figure 5 shows that a Product should satisfy, many Primary_Needs, each of which is detailed by one or more Needs. The state of objects of each of these classes includes a description and a value representing the importance of the need as far as the customer is concerned. So, in the hi-fi example, a Primary_Need object would be created to store details of Good Sound Quality and Features. This would be linked to several Needs objects, including one detailing the requirement for Bass (described as "fairly strong"), one detailing the requirement for Output Power (described as "extremely high") and one detailing the requirement for Reality (described as "above average acceptable").

The HoQ also contains information relating to Engineering Characteristics; this is shown in section 3 of the HoQ in figure3. The information required by this part of the matrix is part of 
the specification for the product. Specifications have to contain requirements, which can be measured, so that it is possible to judge whether a design satisfies the specifications, (i.e. the design targets for the product characteristics). Specification information is often documented as checklists, which are grouped into different categories, [33, 34]. The general categorisation can then be given further detail by sub-dividing the groups into sub-groups, for example the aesthetic properties of a product could be specified in more detail as form, colour, decoration or surface texture.

The product characteristics have been structured using two classes of objects, Aspect which describes the main characteristics of the design and Specification which describes the more detailed characteristics for any particular Aspect. Figure 5 shows that a Product has many Aspects, each of which is detailed by one or more Specifications. The state of objects of the Specification class includes a description and a quantity or quality, i.e. a value, either numerical or descriptive, which can be measured for the characteristic. The current achievable value of a particular product characteristic may well be different to the ideal, or target value. Therefore a further important set of data relates to difficulty ratings, which provide a measure of how difficult it would be to change the value of the characteristics, from the design engineer's perspective. This information is captured within section 6 of the HoQ and is clearly important when determining which characteristics of the product require further design effort. Specification objects also include the important target values achieved through the fuzzy inference and this information is displayed in section 8 of the HoQ. In the hi-fi example, an Aspects object would be created to store details of Bass Loud Speaker Unit. This would be linked to several Specifications objects, including one detailing the Minimum Diameter of Bass Loudspeaker Unit. The current achievable value for this is captured within 
the state of this Specifications object, and in this case could be $200 \mathrm{~mm}$. The target value is also captured as part of the state of this Specifications object, and this is $224.3 \mathrm{~mm}$ (as shown in section 4.3).

The Relationship Matrix, which forms the second segment of the HoQ, matches the needs expressed by the customers to the product design characteristics defined by the design engineers (i.e. the product specification). A relationship exists if a particular product characteristic satisfies a customer need to some extent. The relationship is generally graded as being a strong, medium or weak link, or no link at all. It is important that this information is available to design engineers as it provides the key to continued awareness of how customer needs are being satisfied. If a column of the relationship matrix contains only weak or no links, it may represent a fairly irrelevant product feature as far as achieving customer satisfaction is concerned. There are four classes of objects which record the strength of these relationships, Primary_need_aspect_interrelation (for relationships between Primary_need and Aspect), Primary_need_spec_interrelation (for relationships between Primary_need and Specification), Aspect_interrelation (for relationships between Aspect and Need) and Spec_interrelation (for relationships between Need and Specification).

The fourth segment of the HoQ in figure 3 is the Correlation Matrix, which captures the relationships between different product characteristics. Since the characteristics are stored within objects of the classes Aspect and Specification, there are two classes that capture the correlation information, i.e. Aspect_corr and Spec_correlation. Generally if one design characteristic is changed it will have an effect on some other characteristics, and the extent of the effect is normally recorded at one of the following five levels, strong positive, positive, 
none, negative or strong negative. This is an important part of the HoQ as it enables users to take account of engineering trade-offs. For example, a product feature may appear to be irrelevant to achieving customer satisfaction when the values in its column of the relationship matrix are considered, but changing its design may produce an adverse effect on other highly relevant product features.

Customer needs are only part of the important market information which should be considered during product design. Knowledge of competitors' products, and how well they succeed in satisfying the customer's needs, from the customer's perspective, is also very valuable, as it enables competitive benchmarking, shown in the fifth segment of the HoQ, and the associated technical competitive benchmarks, given in segment 7. Classes used to capture this information all have the prefix 'Competitor' in their names in figure 5. In this research, the company designing the product under consideration is considered to be one of the competitors, so the customer's perception of how well this product satisfies their needs can be captured alongside similar information for competitor products.

\section{Evaluation of Market Information to Prioritise Design Effort}

The Market Driven Design System is designed to provide various types of support to designers aiming to produce attractive products which the customer really wants. This support is provided by an extendable group of integrated, knowledge-based experts that are available in the system. The system provides designers with useful, consistent, reasoned analysis of QFD information, which is valuable, since there are very few software tools which provide such support [35]. More importantly, the information described in the previous sections is freely available to any member of the design team who has access to the 
product model, and can therefore be accessed by many different applications, as shown in figure 1. This raises awareness of market needs and competitor products, across the design and manufacturing functions. Understanding market information is critical to producing products, which the customer wants.

Knowledge based experts, such as the Fuzzy Inference System described in section 4, are part of the Market Driven Design System. Additional expertise can be added to the system using a technique whereby knowledge is stored as objects. The approach used is based on a knowledge representation model (KRM) which enables the expert's knowledge to be captured within an object oriented database [36]. Several software experts have been designed and implemented using this approach, including a system which guides the user through the collection and creation of information needed for the HoQ. There is also a knowledge based expert that can analyse the information to determine which design characteristics should be given priority for design effort. This is important since targeting design effort onto particular aspects of the design can make best use of valuable resources, and simultaneously do most to increase customer satisfaction. The adopted method of performing this analysis is described below, but this is provided as an example of the types of analysis which expert applications within the Market Driven Design System can perform. It is not necessarily recommended as the best algorithm. The analysis can be performed in many different ways, and as the expert is a knowledge-based system, changing the way it performs the analysis is simply achieved by changing the content of its knowledge base. Using the KRM approach, this is achieved by simply changing or adding objects within the database. 
The analysis builds up a matrix of priority indices, in which the rows correspond to individual customer needs and the columns correspond to particular product characteristics. The analysis is performed as follows: -

1. The competitive benchmark figures for each Need are considered in turn, i.e. the rows of the $\mathrm{HoQ}$ are considered one at a time. If the figure for own product is greater than those for the competitor products, it is assumed that no changes to how that particular customer's need is satisfied, are necessary. Hence the entries for each specification in that row of the matrix is given a value zero.

2. The values of each Specification are considered in turn, i.e. the columns of the HoQ are considered one at a time. If the specification value for own product is better than the specification values for the competitors product, it is assumed that no changes are needed to that design characteristic, so the entries for each need in that column of the matrix is given a value zero.

3. The other values in the matrix are calculated, using the equation

$$
\mathrm{v}_{\mathrm{i}}=\left\{\left\{\Sigma \mathrm{f}_{\mathrm{c}}\left(\xi_{\mathrm{j}}\right) \mathrm{G}\left(\mathrm{I}_{\mathrm{j}}\right)\right\}+\mathrm{G}\left(\mathrm{I}_{\mathrm{i}}\right)\right\}
$$

where

$v_{i} \quad$ is the priority index of the matrix element for the Specification and Need currently under consideration

$G\left(I_{i}\right)$ is the inter-relation value for the Specification and Need currently under consideration

$f_{c}\left(\xi_{j}\right)$ is the correlation value for the Specification currently under consideration and the $\mathrm{jth}$ Specification $(1<=\mathrm{j}<=$ number of Specifications recorded $)$

$G\left(I_{j}\right)$ is the inter-relation value for the $j$ th Specification 
4. The matrix entries for each Specification (column) are totalled.

5. The Specifications (design characteristics) are prioritised according to the total values.

Further details of the concept and implementation of the KRM may be found in [36] and of its application in the area of design for quality in [16].

\section{Conclusions}

The challenges of effectively modelling, using and sharing valuable, yet imprecise, nontechnical market information have been addressed through the specification of a comprehensive design support system, called the Market Driven Design System. This intelligent support environment clarifies the design task by using fuzzy inference to translate poorly expressed requirements into clearly quantifiable needs, enabling target values for product characteristics to be determined. The design system enables an extended, multidiscipline design team to make better use of market information. The customer requirements information, design specifications, the related product characteristics and design analysis (using QFD and other techniques) is collected and captured within database systems, so it can be easily shared, updated and reanalysed whenever required throughout the design process. Evaluation of the market information, and associated design features is supported by a set of knowledge based tools available within the support environment. Knowledge can easily be added or modified within the support environment.

The individual elements of the Market Driven Design System have all been implemented and tested, using object oriented database systems and $\mathrm{C}++$ programming language and reports of 
these implementations can be found in [27], [36] and [16]. Currently, work is being done to implement a comprehensive, integrated version of the system, on a personal computer platform, using Objectstore, object-oriented database system, and Visual C++. Further work is also being carried out into the required functionality of further knowledge-based experts to support evaluation of the design in terms of customer satisfaction. 


\section{References}

[1] Ottum, B D \& Moore, W L, 1997, The Role of Market Information in New Product Success/Failure, Journal of Product Innovation Management, 14:258-273

[2] Bennett, D J \& Forrester, P L, 1993, Market-focused Production Systems: Design and Implementation (London: Prentice Hall).

[3] Kohli, A K \& Jaworski, B J, 1990, Market Orientation: The Construct, Research Propositions and Managerial Implications, Journal of Marketing, 54: 1-18 (April 1990)

[4] Harding, J A, and Popplewell, K, 1996, 'Driving Concurrency in a Distributed Concurrent Engineering Project Team: A Specification for an Engineering Moderator', International Journal Production Research, Vol: 34 No: 3 pp 841-861

[5] Harding, J A, Omar, R A and Popplewell, K, 1999, 'Application of QFD within a concurrent engineering environment', International Journal of Agile Management Systems, ISSN: 1465-4652, 1(2) pp 88-98.

[6] Hacker, W, 1997, 'Improving engineering design - contributions of cognitive ergonomics', Ergonomics, Vol40, No:10, pp 1088-1096.

[7] Cohen L, 1995, Quality Function Deployment: How to make QFD work for you, Addison-Wesley, One Jacob Way, Massachusetts, ISBN 0-201-63330-2.

[8] Ulrich, K T \& Eppinger S D, 1995, Product Design and Development, McGraw-Hill

[9] Kano, N, Seraku, N, Takahashi, F \& Tsuji S, 1984, Attractive quality and must-be quality. Hinshitsu, 14(2), 39-48 (The Japan Society for Quality Control)

[10] Hauser, J R, and Clausing, D, 1988, 'The House of Quality', Harvard Business Review, pp 63-72.

[11] Zairi, M, 1993, 'Quality Function Deployment: A Modern Competitive Tool', EFQM, TQM Practitioner Series.

[12] Clausing, D and Pugh, S, 1991, 'Enhanced Quality Function Deployment'. In Proceedings of the Design Productivity International Conference, Honolulu pp15-25.

[13] Bossert, J L, 1991, Quality Function Deployment, A Practitioner's Approach (New York: ASQC Quality Press, Marcel Dekker).

[14] Lo, L T \& Kolence, K W, 1994, The House of Quality and Service Management, CMG Proceeding, Vol 1, pp521-532 
[15] Clausing, Don, 1994, 'Total quality development: a step-by-step guide to world-class concurrent engineering'. ASME Press, The American Society of Mechanical Engineers. ISBN 0-7918-0035-0.

[16] Omar, A R, 1998, Quality Function Deployment Opportunities in Product Model Supported Design, PhD Thesis, Dept of Manufacturing Engineering, Loughborough University, UK.

[17] Omar, A R, Harding, J A, and Popplewell, K, 1999, "Design for Customer Satisfaction: An Information Modelling Approach", Integrated Manufacturing Systems, (The International Journal of Manufacturing Technology Management), ISSN 0957-6061, 10(4), pp 199-209.

[18] Hales, R F, 1993, 'Quality Function Deployment in Current Product/Process Development', IEEE Symposium on Computer Based Medical Systems, pp 28-33.

[19] Cox, E 1994, The Fuzzy Systems Handbook: a practitioner's guide to building, using, and maintaining fuzzy systems, AP Professional, Cambridge, MA, U.S.A.

[20] Zadeh, L. A. 1965 "Fuzzy Sets", Information and Control, Vol. 8, New York: Academic Press, pp. 338-353.

[21] Bossert, J L, 1991, Quality Funtion Deployment - A Practitioner's Approach, ASQC Quality Press, Marcel Dekkes Inc.

[22] Saaty, T. L. 1980, The Analytic Hierarchy Process, McGraw-Hill, New York.

[23] Saaty, T. L. 1994, Fundamentals of Decision Making and Priority Theory The Analytic Hierarchy Process Series, Vol 4 RWS Publications.

[24] Dyer, R F and Forman E H, 1991, An Analytic Approach to Marketing Decisions, Prentice Hall, Englewood Cliffs, New Jersey.

[25] Lu M H, Madu C N, Kuei C H and Winokur D, 1994, Integrating QFD, AHP and Benchmarking in Strategic Marketing, Journal of Business and Industrial Marketing, Vol 9 No 1, pp 41-50

[26] Madu C N and Kuei C H, 1993, Stategic Total Quality Management, in Madu CN (ed.) Management of New Technologies for Global Competitiveness, Quorum books, Westport, CT, U.S.A.

[27] Fung, R Y K, 1997, An Intelligent Hybrid Model for Customer Requirements Interpretation and Product Design Targets Determination, $\mathrm{PhD}$ Thesis, Dept of Manufacturing Engineering, Loughborough University, UK.

[28] Zadeh, L. A. 1973 "Outline of a New Approach to the Analysis of Complex Systems and Decision Processes", IEEE Trans. Systems, Man, and Cybernetics 3, pp. 28-44. 
[29] Krause, F L, Kimura, F, Kjellberg, T, Lu, S C Y, 1993, 'Product Modelling', Annals of the CIRP, vol 42/2/1993.

[30] Gu, P and Chan, K, 1995, 'Product Modelling Using STEP', Computer-Aided Design, Vol27, No: 3, pp 163-179.

[31] McKay, A, Erens, F and Bloor, M S, 1996, 'Relating Product Specifications and Product Definitions in a Product Model', Research in Engineering Design, Vol. 2, pp 63-80.

[32] Quatrani, Terry, 1998, Visual Modeling with Rational Rose and UML, Addison Wesley.

[33] Tjalve, E, 1979, A Short Course in Industrial Design, Newnes-Butterworths, Scotland, ISBN 0-408-00388-X.

[34] Hubka, V and Eder, W E, 1988, Theory of Technical Systems: a Total Concept Theory for Engineering Design, Springer-Verlag, Berlin, ISBN 0-387-17451-6

[35] Syan, C S \& Menon, U, 1994, Concurrent Engineering: Concepts, Implementation and Practice', Chapman \& Hall, London.

[36] Harding J A, 1996, A Knowledge Representation Model to Support Concurrent Engineering Team Working, $\mathrm{PhD}$ Thesis, Dept of Manufacturing Engineering, Loughborough University, UK. 


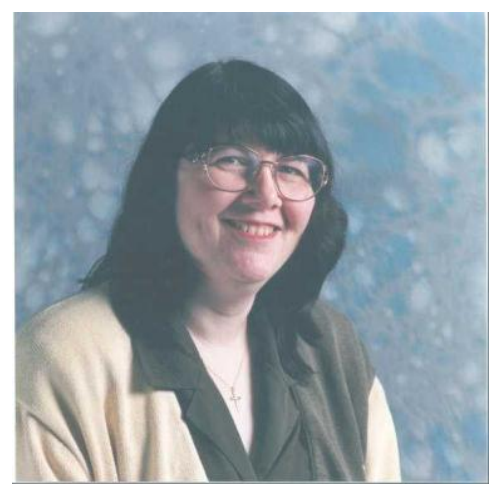

Dr Jenny Harding joined Loughborough University in 1992, and is currently a Research Fellow in the Wolfson School of Manufacturing and Mechanical Engineering. She also has 18 years industrial and commercial experience, working in both textile and engineering industries. Her most recent industrial experience, prior to joining the University, was working for 7 years in metrology research and development where her responsibilities included mathematical modelling, software design and production. Her current research activities are in the areas of information modelling and enterprise design. In addition to her current work, her research interests include Design for Quality, performance driven factory design and applications of artificial intelligence.

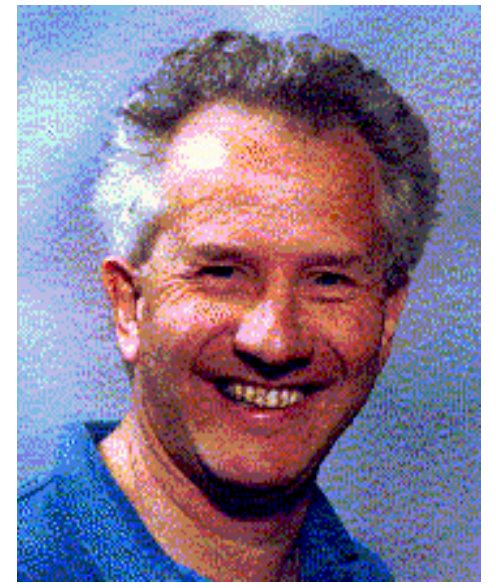

Dr Keith Popplewell started his career in operational research in general, and specialised in computer aided engineering and production planning systems design with Raleigh Industries and Boots Company plc. During this time he took a doctorate in manufacturing engineering at the University of Nottingham. Subsequently he became technical director in a software house specialising in the design, development and implementation of CAE systems, before joining the Department of Manufacturing Engineering at Loughborough University in 1985. His research interests centre on the application of intelligent computing methods to the modelling and design of both engineering products and manufacturing systems. 


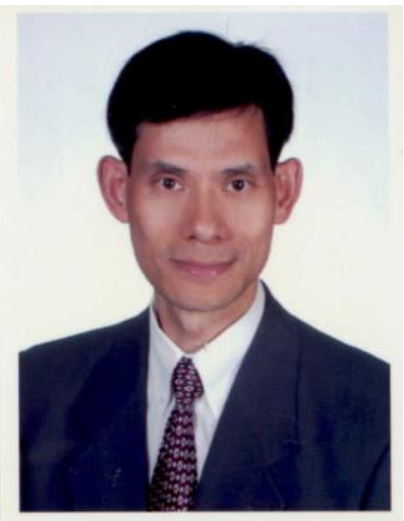

Dr. Richard Y. K. Fung obtained his B.Sc. Honours degree in Production Engineering and his Master of Philosophy in Manufacturing Resource Planning both from the Aston University in Birmingham, UK and his Ph.D. in Customer Requirement Management from Loughborough University, UK. He worked in the industry for over twelve years, has been involved in different manufacturing areas including product development, production planning and control, design and implementation of management information system, as well as management consultancy in UK. Dr. Fung joined the City University of Hong Kong in 1989, and he is now an Associate Professor in the Department of Manufacturing Engineering and Engineering Management. His current teaching and research areas cover Quality Management, Customer Requirements Analysis, Quality Function Deployment, One-of-aKind Production, Supply Chain Management, and applications of Artificial Intelligence Techniques, such as Neural Network, Fuzzy Systems and Genetic Algorithms, in solving industrial / manufacturing problems.

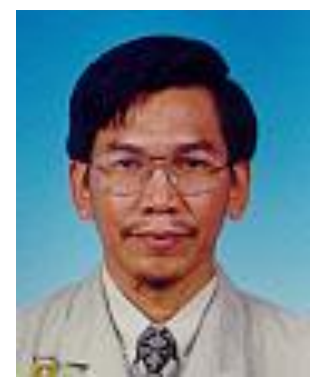

Assoc. Prof. Ir. Dr. Abdul Rahman Omar obtained his BEng in Mechanical Engineering at MARA University of Technology, Malaysia (1984) and continued his studies at Sheffield University, United Kingdom (1989/90) where he obtained his MSc in Control Systems. He has been an active researcher in Information Modeling, being a student at Manufacturing Department of Loughborough University from 1994 to 1997 where he obtained his PhD. The title of his thesis is Quality Function Deployment opportunities in Product Model Supported Design. He is still involved in this research and is currently applying this concept in a Concurrent Engineering based environment. At the present time Dr. Omar is serving as a lecturer at Faculty of Mechanical Engineering, MARA University of Technology, Malaysia, a position he has held since 1985 . 


\section{Figure Legends:}

Figure 1: Sharing Information Between Extended Design Team Members

Figure 2: Functionality of Market Driven Design System

Figure 3: The Functional Building Blocks of the House of Quality

Figure 4: Architecture of Fuzzy Inference System

Figure 5: Class diagram showing relationships between objects in the Market Information section of the Product Model 


\begin{tabular}{|c|c|c|}
\hline$\ldots$ & .. & $\begin{array}{llllllllllllll}\ldots & \ldots & \ldots & \ldots & \ldots & \ldots & \ldots & \ldots & \ldots & \ldots & \ldots & \ldots & \ldots & \ldots\end{array}$ \\
\hline \multirow[t]{5}{*}{8} & $\mathrm{HOW}$ & many discs do you want your CD player to hold? \\
\hline & A & Less than 3 discs \\
\hline & $\mathrm{B}$ & Less than 5 discs \\
\hline & $\mathrm{C}$ & Less than 10 discs \\
\hline & $\mathrm{D}$ & More than 10 discs \\
\hline \multirow[t]{4}{*}{9} & \multicolumn{2}{|r|}{ What is the major inconvenience in changing CDs? } \\
\hline & A & Take too long to change \\
\hline & $\mathrm{B}$ & Have to change CDs too frequently \\
\hline & $\mathrm{C}$ & Others, please specify \\
\hline \multirow[t]{5}{*}{10} & \multicolumn{2}{|r|}{ How long would you expect an automatic disc change to take? } \\
\hline & A & Less than 2 seconds \\
\hline & $\mathrm{B}$ & Less than 4 seconds \\
\hline & $\mathrm{C}$ & Less than 6 seconds \\
\hline & $\mathrm{D}$ & More than 6 seconds \\
\hline \multirow[t]{9}{*}{11} & \multicolumn{2}{|r|}{$\begin{array}{l}\text { Rank the relative importance of the following factors if you are } \\
\text { going to buy a CD player ( } 1=\text { most important, } 8=\text { least important })\end{array}$} \\
\hline & A & Sound quality \\
\hline & $\mathrm{B}$ & Reputation of the brand \\
\hline & $\mathrm{C}$ & Price \\
\hline & $\mathrm{D}$ & Size \\
\hline & $E$ & Appearance \\
\hline & $\mathrm{F}$ & Ease and flexibility of disc loading \\
\hline & G & $\begin{array}{l}\text { Ease of access to large number of songs (for } \\
\text { example having more than } 1 \mathrm{CD} \text { loaded at a time) }\end{array}$ \\
\hline & $\mathrm{H}$ & Speed of access between songs \\
\hline \multirow[t]{8}{*}{12} & \multicolumn{2}{|r|}{$\begin{array}{l}\text { Which part(s) of your CD player do you think need improvement? (Tick } \\
\text { all relevant items) }\end{array}$} \\
\hline & A & CD loading mechanism \\
\hline & $\mathrm{B}$ & Speed of accessing songs \\
\hline & $\mathrm{C}$ & Ease of changing CDs \\
\hline & $\mathrm{D}$ & Sound quality \\
\hline & $E$ & Appearance \\
\hline & $\mathrm{F}$ & Size \\
\hline & G & Others, please specify \\
\hline$\ldots$ & & $\begin{array}{llllllllllllll} & \ldots & \ldots & \ldots & \ldots & \ldots & \ldots & \ldots & \ldots & \ldots & \ldots & \ldots & \ldots & \ldots\end{array}$ \\
\hline
\end{tabular}

Table 1: Example questions from customer surveys 


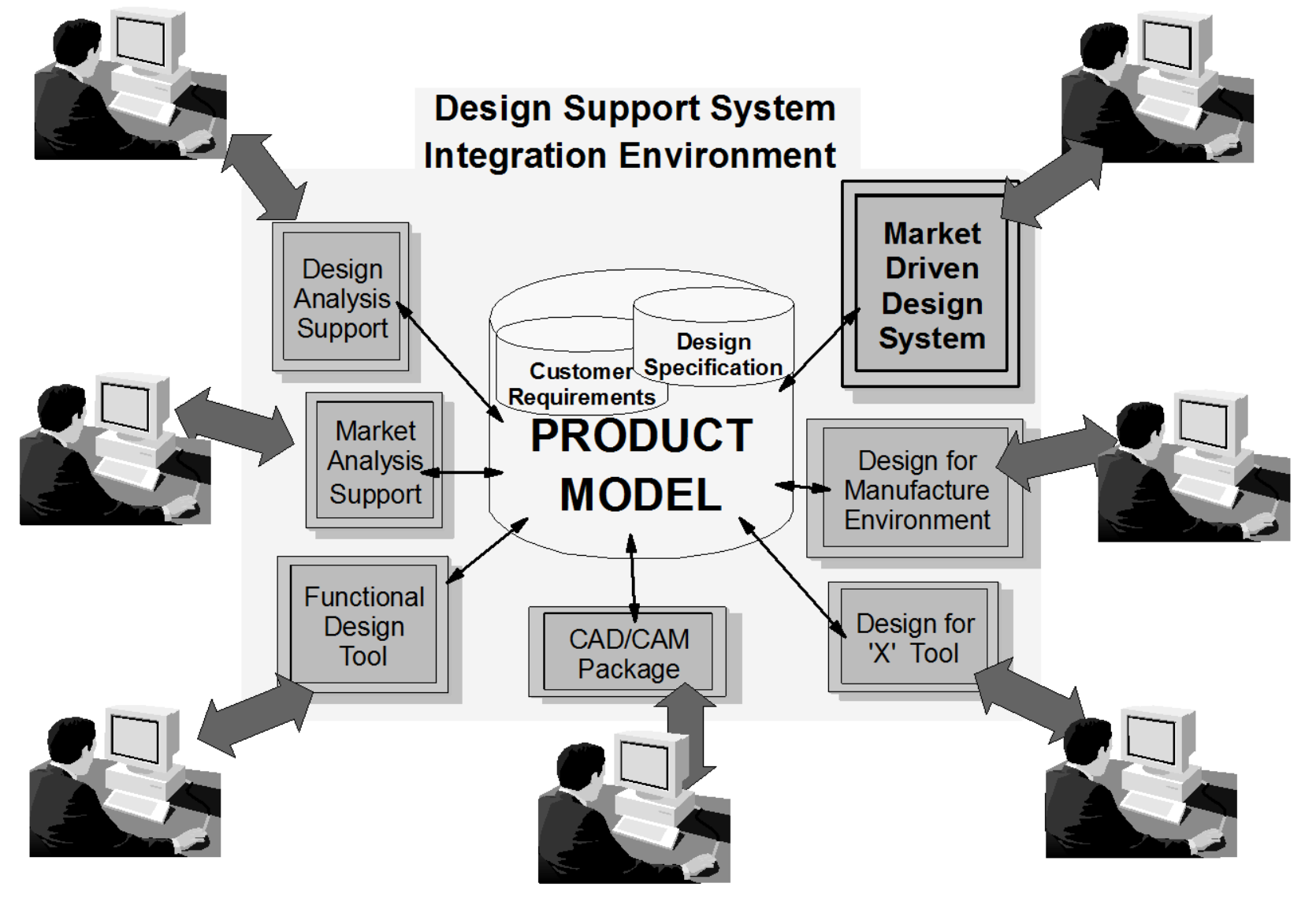

Figure 1: Sharing Information Between Extended Design Team Members 


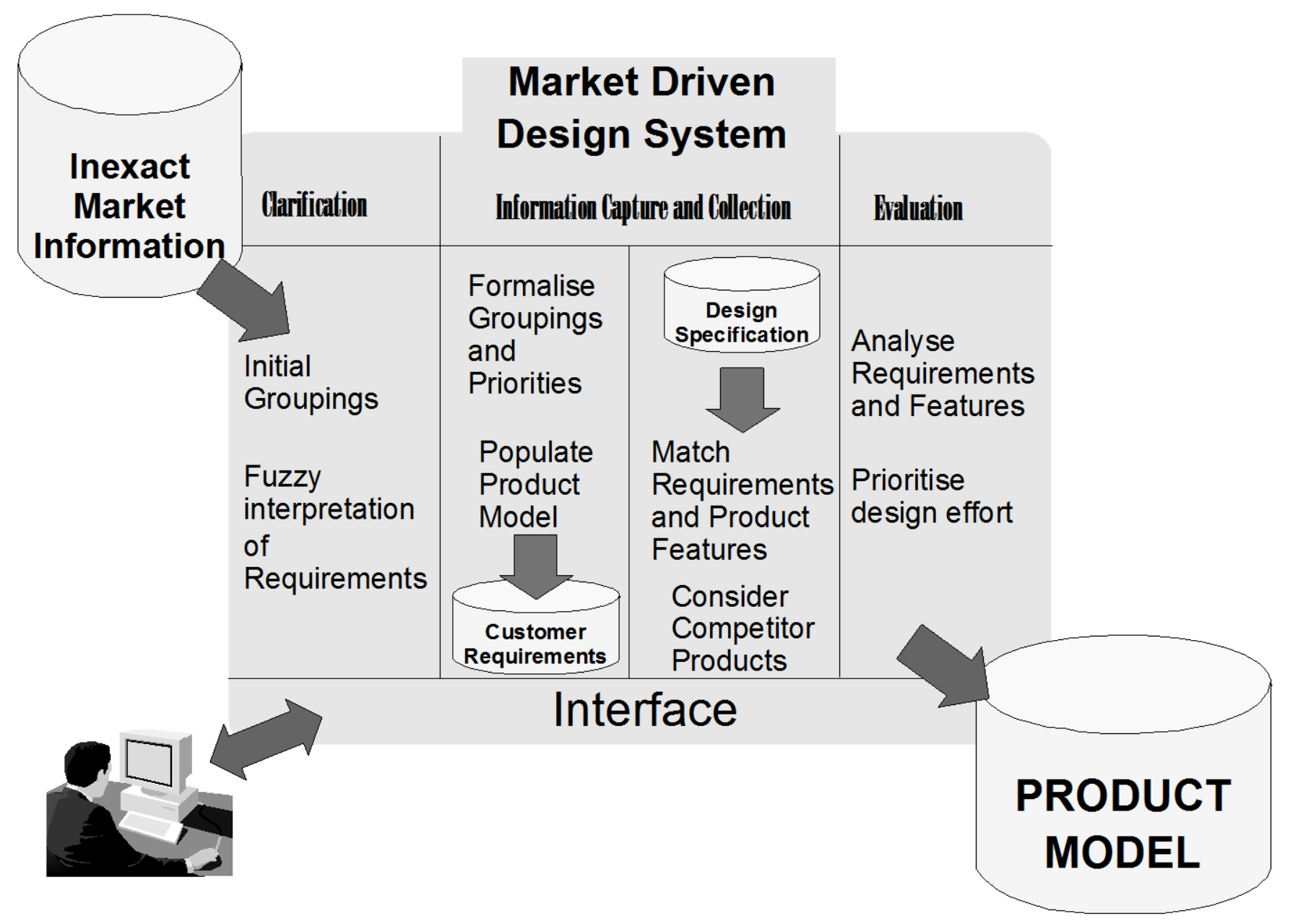

Figure 2: Functionality of Market Driven Design System 


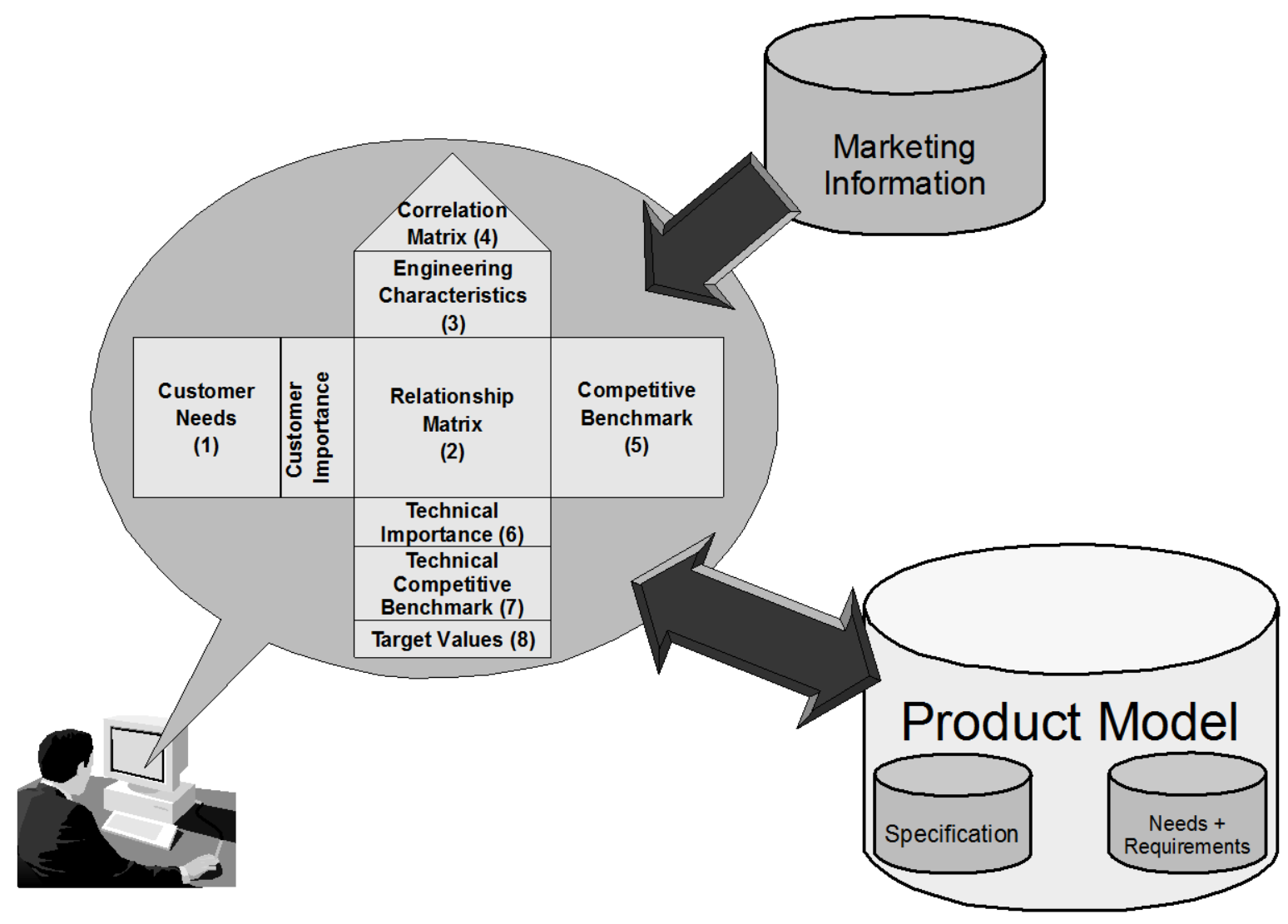

Figure 3: The Functional Building Blocks of the House of Quality 


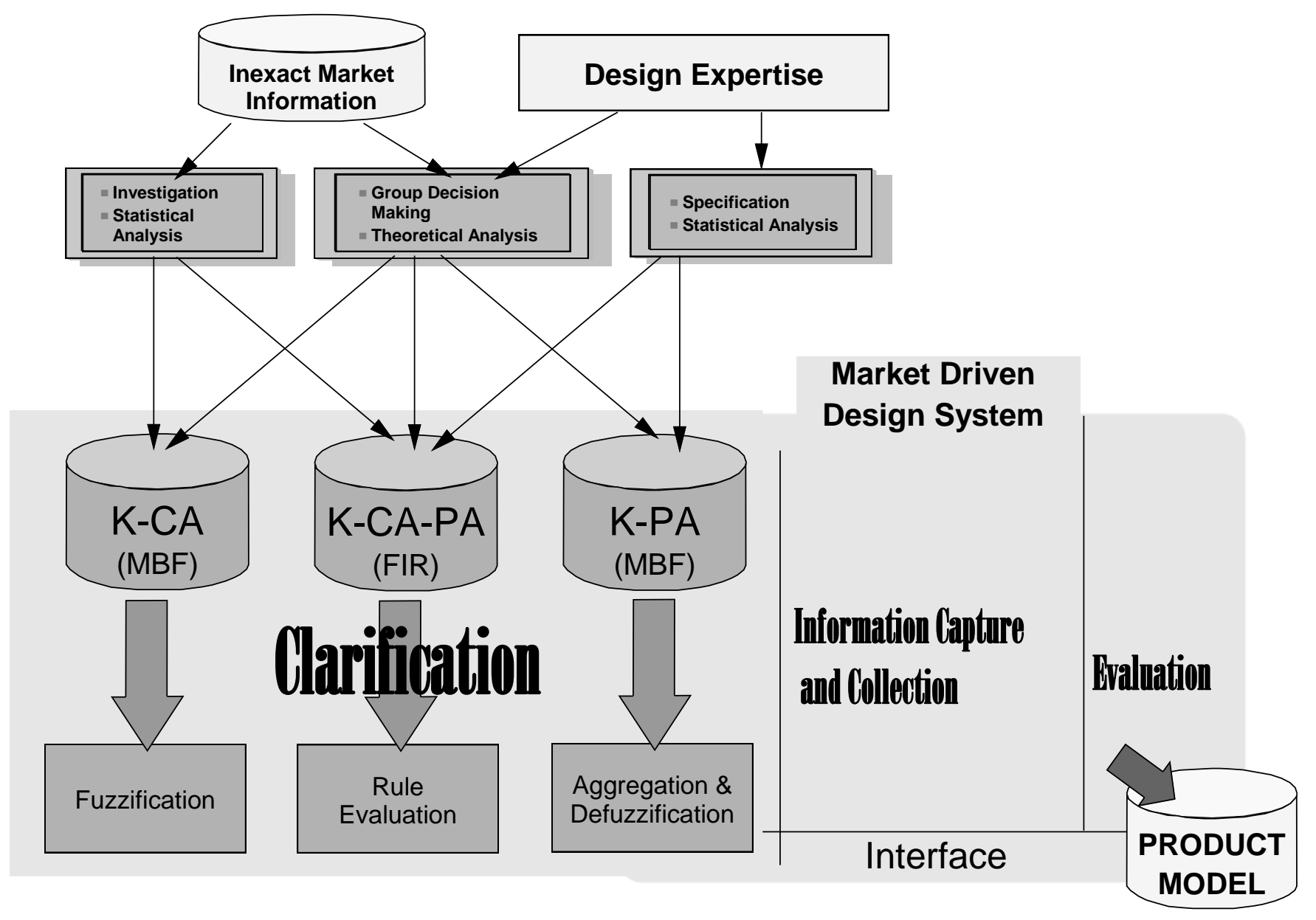

K-CA Knowledge about Customer Attributes / Customer Requirements (The Inputs)

K-PA Knowledge about Product Attributes / Engineering Characteristics (The Outputs)

K-CA- Knowledge about the relationships between Customer Requirements and Product

PA Attributes

MBF Membership Functions

FIR Fuzzy Inference Rules / Propositions

Figure 4: Architecture of Fuzzy Inference System 


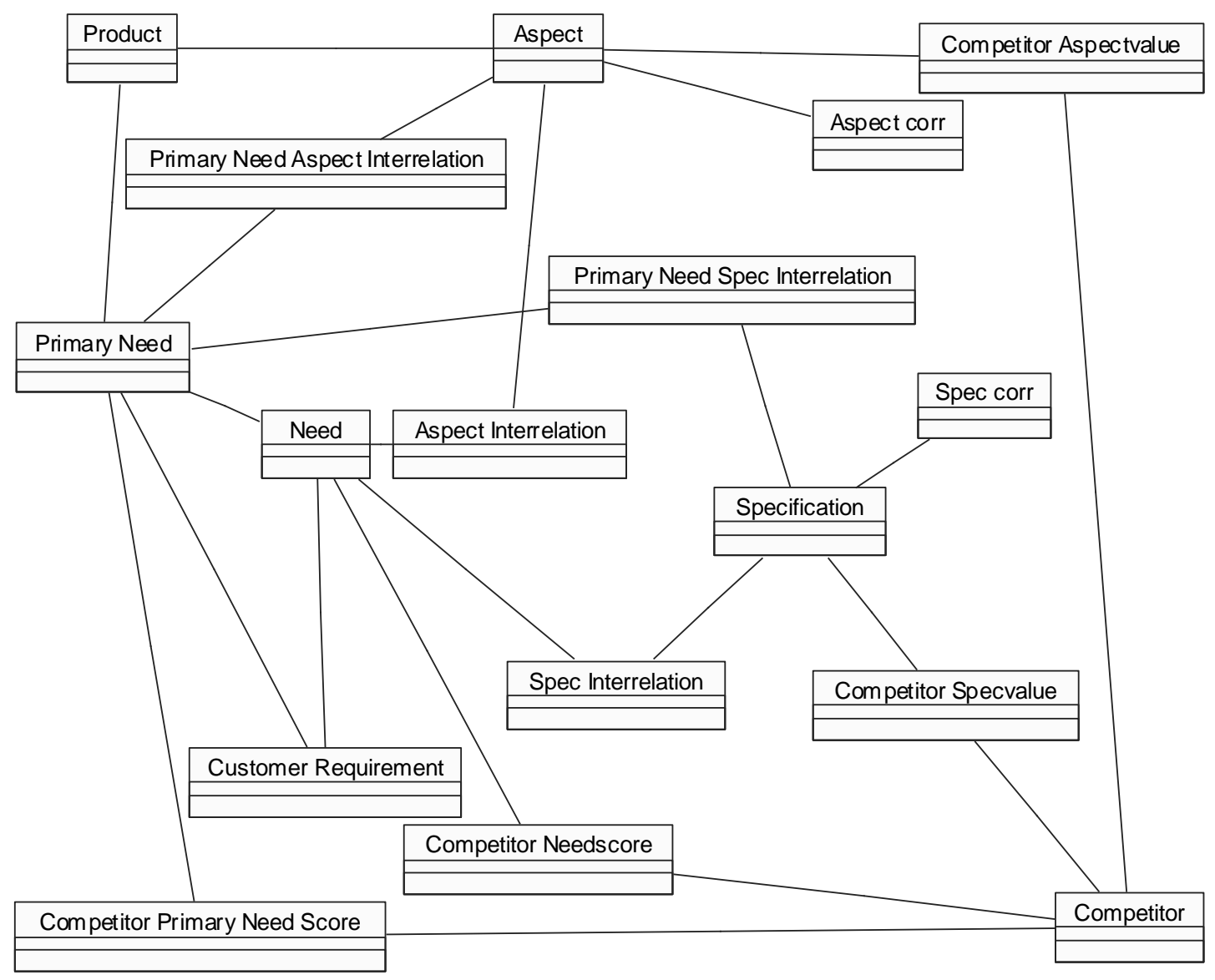

Figure 5: Class diagram showing relationships between objects in the Market Information section of the Product Model 